\title{
Analysis Quality Control Document
}

National Cancer Institute

\section{Source}

National Cancer Institute. Analysis Quality Control Document. NCI Thesaurus. Code C115633.

Records of the quality control (QC) procedures planned for the analysis programs, and the outputs of said QC procedures. 